\title{
The Feasibility and Acceptability of Project POWER: A Cognitive-Behavioral Mindfulness-Infused Group- Based Mental and Sexual Health Intervention Among Young Pregnant Women in Liberia
}

Tamora A. Callands ( $\nabla$ tamcall@uga.edu )

University of Georgia

Kandyce Hylick

University of Georgia

Alethea Desrosiers

Boston College

Shantesica M. Gilliam

University of Georgia

Erica N. Taylor

University of Georgia

Josalin J. Hunter

University of North Carolina

Nathan B. Hansen

University of Georgia

Research Article

Keywords: feasibility and acceptability, POWER, mental and sexual health

Posted Date: December 15th, 2021

DOI: https://doi.org/10.21203/rs.3.rs-1043881/v1

License: (c) (i) This work is licensed under a Creative Commons Attribution 4.0 International License.

Read Full License 


\section{Abstract \\ Background}

Following 14 years of civil war in Liberia, war-exposure, gender-based violence, and extreme poverty have been identified as key challenges to the mental and sexual health of young pregnant women, and the health of their unborn children. Despite ongoing efforts to rebuild the country's healthcare infrastructure, empirical research and interventions focused on addressing the consequences of war on the mental and sexual health of young pregnant women in Liberia are severely limited. To address these concerns, we developed Project POWER (Progressing OurWell-being, Emotions, and Relationships) (POWER), a mindfulness-infused cognitive-behavioral intervention for young adult pregnant women. This study sought to: 1) assess the feasibility and acceptability of POWER; and (2) determine the preliminary efficacy of POWER for improving mental and sexual health outcomes among Liberian war-exposed pregnant young adult women.

\section{Methods}

Eighty-seven women ages 18-25 years were recruited from three catchment areas in Monrovia, Liberia. Participants participated in one of two ten-session programs delivered over 5-weeks: POWER or a control group (a health education program). Feasibility and acceptability of POWER were examined using program log (e.g., the number of participants screened and enrolled, facilitator satisfaction, etc.) data from an exit interview.

\section{Results}

Preliminary efficacy of POWER's effects on mental and sexual health outcomes was assessed using a series of four one-way repeated measures ANOVA with time and group as predictors. Analyses provided preliminary support for the feasibility and acceptability of POWER. Preliminary efficacy of POWER showed significant reductions in depression symptoms, PTSD symptoms, prenatal distress, and transactional sex over time.

\section{Conclusions}

Findings suggest that POWER may be a feasible and acceptable intervention to promote mental and sexual health for young adult pregnant women in Liberia. Future research is needed to determine the efficacy of POWER on a larger scale in Liberia.

\section{Introduction}


Exposure to traumatic events has been consistently linked to mental and sexual health problems in postconflict settings $[1,2,3]$. Between 1989 and 2003, Liberia experienced a deadly civil war that resulted in over 150,000 deaths and war-related trauma exposure in $60 \%$ of the population [4]. Human rights violations (e.g., sexual violence and torture) were common during the war and have been associated with adverse mental and sexual health outcomes for many Liberians [5], including high rates of depression and post-traumatic stress [6]. Sexual and gender-based violence (SGBV) and unsafe sexual practices (e.g., transactional sex) during and post-conflict have also been linked to increased rates of sexual and reproductive health problems [7, 8], including sexually transmitted diseases (STIs), abortions, and unwanted pregnancies $[9,5]$. Existing health services are still recovering from the war and not equipped to address unmet mental and sexual health care service needs of women $[3,10,11,12]$.

For pregnant young women in Liberia and other low- and middle-income countries (LMICS), the need for integrated mental and sexual health services is high. Prenatal distress - stress, anxiety, or depression during pregnancy - is significantly higher in LMICs than in high-income countries [13]. Chronic stress throughout pregnancy places women at risk for neonatal and obstetric complications, such as premature birth, postpartum depression, and unplanned cesarean delivery [14]. In addition to negative impacts on mothers, prenatal distress during pregnancy is associated with adverse perinatal outcomes among infants, such as low birth weight and preterm birth $[15,16]$. Implementing mental and sexual health interventions for pregnant women in LMICs is essential for women's health and their unborn children [17].

To address the need for integrated mental and sexual health services for young Liberian women, we developed and culturally adapted a mindfulness-infused cognitive-behavioral intervention called Progressing O ur Well-being, Emotions, and Relationships (POWER) to improve young pregnant women's mental and sexual health in Liberia (funded by NIH/FIC grant number 1K01TW009660). There is strong evidence supporting the effectiveness of mindfulness-based practices-paying attention in the present moment without judgment-in reducing anxiety, depression, and general psychological distress in pregnant women $[18,19]$. The current study's objectives are: (a) to assess the feasibility and acceptability of POWER and (b) to evaluate the preliminary efficacy of POWER on mental and sexual health outcomes among war-exposed pregnant young adult women in Liberia.

\section{Methods}

\section{Participant Recruitment and Procedures}

Participants were recruited using purposive sampling in three catchment areas located in Montserrado county-the most populated county in Liberia-through a well-known local health clinic. Two catchments received POWER and one received the control condition. One nurse per clinic facilitated recruitment through: (1) gauging interest in the study during prenatal care appointments, (2) asking potential participants if they knew other pregnant women (i.e., snowball sampling), and (3) using existing clinic programming roasters. If the potential participant expressed interest in the program, the nurse provided their contact information to a research team member, who then scheduled an in-person screening. 
Study inclusion criteria were: (a) receiving prenatal or health services through the clinic; (b) 18-25 years old; (c) residing in Monrovia, and (d) between 13 and 24 weeks of gestational age. Exclusion criteria included pregnancy-related medical problems. The gestation age between 13 and 24 weeks ensured that women were past the first trimester, which comprises several risks and decisions regarding pregnancy. This time frame also increased the likelihood that women completed the 3-month follow-up before delivery. Those interested in participating who met inclusion criteria provided informed consent to participate in the study. Participants received the equivalent of $\$ 9$ ( $\$ 1$ for travel, $\$ 3$ for a meal, and $\$ 5$ for completing assessments). Participation in the study was voluntary and confidential, and healthcare services were not affected by participation.

The study was approved by both a US-based and Liberia -based Institution Review Board: The University of Georgia's Human Research Protection Program and The University of Liberia (UL)-Atlantic Center for Research and Evaluation (ACRE) Africa.

\section{Study Design}

This open pilot study used a two-group (POWER and control) pre-post design to explore feasibility, acceptability and preliminary efficacy of POWER among young pregnant women. Both groups completed quantitative assessments on mental and sexual health at baseline and 3-month follow-up. Participants in the POWER group completed a mixed-methods exit interview to assess experiences with the intervention (e.g., satisfaction with facilitators and implementation of adaptive coping skills).

Before conducting the open-pilot study, three Liberian experts reviewed intervention and control group materials extensively. Experts were mental health services providers or sexual health services providers (i.e., social workers, nurses, midwives). We conducted a two-week pre-pilot phase for both conditions to gather feedback on content, acceptability, and cultural relevance of intervention materials from a matched sub-sample of young pregnant women. Facilitator training was conducted for both conditions. The $\mathrm{PI} /$ developer of POWER delivered a one-week facilitator trainings for both conditions. During the prepilot, participants provided feedback to facilitators regarding their facilitation skills. Facilitators participated in weekly supervision with the PI and program supervisor.

\section{POWER Condition}

POWER is a ten-session intervention delivered two times per week over five weeks. It incorporates skills and concepts derived from mindfulness and cognitive-behavioral therapy-based interventions. The primary goals of POWER are to: (1) increasing knowledge and awareness of stress, emotional regulation, and prenatal distress; (2) promoting understanding and knowledge of sexual values and risk reduction strategies; and (3) increasing knowledge and awareness of healthy interpersonal relationships (see Table 1 for more session details). In the open trial, sessions were cofacilitated by a nurse and social worker, and each session lasted approximately 90 minutes. 
Table 1

Power Curriculum Outline

\begin{tabular}{|c|c|c|}
\hline Session & Theme & Activities \\
\hline \multirow[t]{5}{*}{1} & \multirow{5}{*}{$\begin{array}{l}\text { Introduction and trauma } \\
\text { psycho education }\end{array}$} & - Establishing a safe group environment \\
\hline & & - Introduction and overview \\
\hline & & - Establishing group rules \\
\hline & & - Identifying personal goals \\
\hline & & - Finding a positive focus \\
\hline \multirow[t]{4}{*}{2} & \multirow{4}{*}{$\begin{array}{l}\text { Emotion Regulation and } \\
\text { Stress Management }\end{array}$} & - Opening the session \\
\hline & & - Introducing emotion regulation \\
\hline & & $\begin{array}{l}\text { - Presenting coping strategies for stress management (Body } \\
\text { scan activity) }\end{array}$ \\
\hline & & - Stress management activity ("Be good to yourself") \\
\hline \multirow[t]{5}{*}{3} & \multirow[t]{5}{*}{ Adaptive Coping } & - Opening the session \\
\hline & & - Deep Breathing exercise \\
\hline & & - Introducing adaptive coping \\
\hline & & • “Let's Talk It Out” Group Activity \\
\hline & & $\begin{array}{l}\text { - Practicing adaptive coping techniques (muscle relaxation } \\
\text { exercise) }\end{array}$ \\
\hline \multirow[t]{4}{*}{4} & \multirow{4}{*}{$\begin{array}{l}\text { Prenatal Distress/Mental } \\
\text { Health }\end{array}$} & - Opening the session \\
\hline & & - Introducing maternal mental health and prenatal distress \\
\hline & & - Mindfulness meditation activity \\
\hline & & $\begin{array}{l}\text { - Learning skills to reduce long-term stress and mental health } \\
\text { problems }\end{array}$ \\
\hline \multirow[t]{4}{*}{5} & \multirow{4}{*}{$\begin{array}{l}\text { Introduction to Sexual } \\
\text { Health }\end{array}$} & - Opening the session \\
\hline & & $\begin{array}{l}\text { - Introducing sexual health and sexually transmitted } \\
\text { infections }\end{array}$ \\
\hline & & - Identifying ways to get tested \\
\hline & & - Sexual health-related activity \\
\hline
\end{tabular}




\begin{tabular}{|c|c|c|}
\hline Session & Theme & Activities \\
\hline \multirow[t]{4}{*}{6} & \multirow{4}{*}{$\begin{array}{l}\text { Sexual Values and Risk } \\
\text { Reduction Knowledge }\end{array}$} & - Opening the session \\
\hline & & - Discussing the difference between power and pressure \\
\hline & & - Learning about consent and healthy sexual decision making \\
\hline & & - Condom use activity \\
\hline \multirow[t]{4}{*}{7} & \multirow{4}{*}{$\begin{array}{l}\text { Introduction to Healthy } \\
\text { Relationships }\end{array}$} & - Opening the session \\
\hline & & $\begin{array}{l}\text { - Identifying the characteristics of healthy and unhealthy } \\
\text { relationships }\end{array}$ \\
\hline & & - Learning the benefits of healthy relationships \\
\hline & & - Relationship Activity \\
\hline \multirow[t]{5}{*}{8} & \multirow{5}{*}{$\begin{array}{l}\text { Interpersonal } \\
\text { Relationships and } \\
\text { Communication Skills }\end{array}$} & - Opening the session \\
\hline & & - Developing ways to increase social support \\
\hline & & - Developing and refining communication skills \\
\hline & & - Identifying communication styles \\
\hline & & $\begin{array}{l}\text { - Learning strategies for conflict resolution (interpersonal } \\
\text { relationships and listening) }\end{array}$ \\
\hline \multirow[t]{5}{*}{9} & \multirow{5}{*}{$\begin{array}{l}\text { Relating to your Body } \\
\text { and Baby After Birth }\end{array}$} & - Opening the session \\
\hline & & - Introduction to parenting \\
\hline & & $\begin{array}{l}\text { - Learning strategies to effectively coping with new } \\
\text { motherhood }\end{array}$ \\
\hline & & - Developing a viable support network with other parents \\
\hline & & $\begin{array}{l}\text { - Learning techniques to combat common issues that arise } \\
\text { with newborns (Breastfeeding, "Why is your baby crying?" } \\
\text { activity) }\end{array}$ \\
\hline \multirow[t]{4}{*}{10} & \multirow{4}{*}{$\begin{array}{l}\text { Building a Support } \\
\text { Network and Celebration }\end{array}$} & - Opening the session \\
\hline & & - Discuss building a support network \\
\hline & & - Reviewing previous sessions \\
\hline & & - Celebrating the end of the program \\
\hline
\end{tabular}

\section{Control Condition}

Our team developed a general health education program for the control condition consisting of tensessions delivered two times a week over five weeks. The general health curriculum provided information about the body and infectious disease control, hygiene, water and food safety, nutrition, substance use, 
mosquitos and malaria, hemorrhagic fevers, and infectious diseases. Each session lasted approximately 90 minutes. Intervention content was delivered by a nurse who was trained in the curriculum.

\section{Measures}

All study measures were culturally adapted using Beaton's [20] guidelines for cross-cultural adaptation of self-reported measures. Due to high illiteracy rates, all measures were administered verbally to the participant using a computer-assisted program by a trained female research assistant. Our team collected demographics (i.e., age, level of education, relationship status, number of children) and secondary outcome measures (i.e., mental and sexual health questions) from participants at baseline and 3-month follow-up.

\section{Primary Outcomes: Feasibility and Acceptability of POWER}

We assessed the feasibility of POWER by examining the following: (1) number of potential participants screened; (2) number enrolled, (3) number of participants who completed both baseline and 3-month follow-up assessments, (4) average number of sessions attended, and (5) number of participants who completed exit interviews.

Program acceptability was operationalized as satisfaction with the process [21, 22]. We assessed the acceptability of POWER by examining the following reports: (1) POWER sessions that were liked most and least, (2) skills learned from POWER, (3) how often participants practiced sessions outside of the group, and (4) participants satisfaction with POWER facilitators.

\section{Secondary Outcome Measures: Mental and Sexual Health}

Patient Health Questionnaire-9 (PHQ-9) [23]. The PHQ-9 assesses nine major depressive disorder symptoms, as defined by the DSM-IV. Participants were asked how often they experienced each symptom over the last two weeks. The responses were modified for this study based on suggestions from the cultural adaptation process. The original range was 0 (not at all) to 3 (nearly every day). The range was modified from 0 (not at all) to 2 (every day) to measure severity. Higher scores on the severity scale indicated that depressive symptoms were more severe. The Cronbach's alpha was .72.

Prenatal Distress Questionnaire (PDQ). The PDQ is an 18-item measure that assesses the extent to which respondents are concerned, troubled, or worried about issues related to their pregnancy [24]. Items are rated on a 3-point Likert scale, 0 (not at all) to 2 (every day). Scores are added to create a total score. Higher scores indicate higher levels of distress. The Cronbach's alpha was .88.

Life Problem Checklist ( $L P C$ ). The LPC is a 28-item measure adapted from the General Life Stressors subscale [24]. Response options range from 1 (nothing like that) to 5 (always). Mean scores are calculated to derive a total score. Higher scores indicate a greater likelihood of stressors taking place. The Cronbach's alpha was 84 . 
PTSD Symptoms (Post Traumatic Stress Disorder Checklist-Civilian Version) (PCL) [26]. The PCL-C is a 17-item PTSD Checklist. Participants rated the severity of PTSD symptoms over the previous 30 days. The adapted response scale ranged from 0 (not at all) to 3 (all the time). The Cronbach's alpha was .76.

Transactional Sex (TSC). The TSC is a 9-item measure adapted from the Transactional Sex Scale [27]. The measure assessed three different behaviors: 1) staying in a relationship longer than one wants; 2) starting a new relationship; 3) engaging in sex strictly for monetary/other goods for three reasons: (1) paying for items they could not buy themselves, (2) paying for food, children's school fees, or taking care of the home, and (3) supporting children or family who depends on them financially. The adapted response scale was dichotomized (yes $=1$ or no $=0$ ). Scores are calculating by summing items.

Participants were considered to have engaged in transactional sex if they indicated they received a score above zero.

\section{Data Analysis}

Descriptives statistics were computed to assess the feasibility and acceptability of POWER. To investigate whether POWER demonstrated efficacy in improving mental and sexual health outcomes, we performed a series of four mixed with time (pre-intervention, post-intervention) as the within-subjects' factor and group (intervention, control) as the between-subjects' factor. Analyses were conducted using SPSS 25.0. Significance was established at an alpha level of .05, two-tailed. Cohen's d represents effect size. Only participants with complete data were included in the analyses. Twenty participants were dropped from analyses: one did not have complete pre-test data, and nineteen did not have post-test data.

\section{Results}

\section{Participant Characteristics}

Eighty-seven women participated in the study ( $\mathrm{n}=45$ in Power; $\mathrm{n}=42$ in control). Table 2 displays demographic characteristics. Participants were $18-25$ years old $(M=20.72, S D=2.24)$. Eight percent of the sample did not attend school, approximately $24 \%$ had a primary school education, $30 \%$ had a secondary education, and $30 \%$ had a high education or higher. The majority of the sample did not have living children (80\% POWER $(n=36), 69 \%$ control $(n=29))$. Only one participant indicated that she was not in a relationship. 
Table 2

Participant characteristics, $(\mathrm{N}=87)$

\begin{tabular}{|c|c|c|c|}
\hline & Overall & POWER & Control \\
\hline & $\mathrm{n}(\%)$ & n (\%) & $\mathrm{n}(\%)$ \\
\hline Age $(M, S D)$ & $20.72(2.24)$ & $20.33(2.14)$ & $21.14(2.25)$ \\
\hline \multicolumn{4}{|l|}{ Education } \\
\hline No School & $6(7.9)$ & $5(11.1)$ & $1(2.4)$ \\
\hline Primary (Grade 1-6) or less & $21(23.9)$ & $8(17.8)$ & $13(31.0)$ \\
\hline Secondary (Grade 7-9) & $30(34.1)$ & $20(44.4)$ & $10(23.8)$ \\
\hline $\begin{array}{l}\text { High School (Grade } 10-12 \text { or } \\
\text { greater) }\end{array}$ & $30(34.1)$ & $12(26.6)$ & $18(42.9)$ \\
\hline \multicolumn{4}{|l|}{ Relationship status } \\
\hline Not in a relationship & $1(1.1)$ & $1(2.2)$ & $0(0.00)$ \\
\hline In a relationship & $86(97.7)$ & $44(97.8)$ & $42(100.0)$ \\
\hline \multicolumn{4}{|l|}{ Any living children } \\
\hline No & $65(73.9)$ & $36(80.0)$ & $29(69.0)$ \\
\hline Yes & $22(24.9)$ & $9(20.0)$ & $13(31.0)$ \\
\hline \multicolumn{4}{|l|}{ Number of times Pregnant } \\
\hline 1 & $57(64.8)$ & $33(73.3)$ & $24(57.1)$ \\
\hline 2 & $18(20.5)$ & $6(13.3)$ & $12(28.6)$ \\
\hline 3 or more & $12(13.6)$ & $6(13.3)$ & $6(14.3)$ \\
\hline
\end{tabular}

\section{Primary Outcomes: Feasibility and Acceptability of POWER}

Feasibility. All screened individuals met study eligibility criteria and enrolled $(n=87)$. The 3-month followup completion rate was $79 \%$. The average number of sessions attended was 8.99 out of 10 for POWER participants and 8.02 out of 10 for control participants. Forty POWER participants completed the exit survey. The control group did not complete an exit survey. Participants indicated that the clinic's location in the community played a large role in their session attendance.

Acceptability. Participants ranked the sessions they liked most and least. The emotion regulation session was ranked highest (77.5\%), followed by healthy relationships (47.5\%) and communication skills (45\%). $67.5 \%$ of participants endorsed 'not applicable' regarding least liked sessions. The remaining participants reported that they liked the sexual health, prenatal distress, and sexual values sessions the least. Deep 
breathing ( $M=2.77$ times per week), muscle relaxation ( $M=3.05$ times per week), meditation $(M=3.15$ times per week), talking to someone ( $M=3.74$ times per week), and listening to music $(M=3.77$ times per week) were the adaptive coping skills practiced most outside of the group.

Based on a 4-point likert scale rating, the average rating for facilitation satisfaction was 2.51 .

Communication was identified as an area for facilitator improvement. Participants reported that the facilitator "could speak and make her words clearer" and "she could speak slower." Participants' feedback about their likes centered on themes of facilitator helpfulness (e.g., "she make me understand"; "she always talks to me to help me manage my stress"; "she is very encouraging people and explains the topics well").

Participants reported positive feelings and also some sadness about program completion. For example, one participant said, "I feel good because it educated me along." Other participants said, "I feel good and bad because the program empowered me by more knowledge... I feel bad because I won't be seeing the program again", and indicated a desire to continue learning (e.g., "I don't want the program to end," "I want to learn more").

\section{Preliminary Efficacy: Mental and Sexual Health Outcomes}

The effect sizes for the secondary outcomes are provided in Table 3. These include Cohen's D's for time, group, and group by time estimates.

Table 3

Effect sizes of Secondary Outcomes

\begin{tabular}{|lllll|}
\hline & PCL & PDQ & TS & PHQ \\
\hline & Partial $\eta^{2}$ & Partial $\eta^{2}$ & Partial $\eta^{2}$ & Partial $\eta^{2}$ \\
\hline Time $^{\mathrm{a}}$ & $.55^{*}$ & $.75^{\star *}$ & $.55^{\star}$ & $1.44^{\star \star *}$ \\
\hline Group & .00 & .44 & .35 & .58 \\
\hline Time $^{*}$ Group & .33 & .06 & $.59^{*}$ & $.80^{*}$ \\
\hline $\begin{array}{l}\text { Note: } \\
.001\end{array}$ & indicates that data was collapsed across pre- and post-intervention. ${ }^{*} p<.05,{ }^{* \star} p<.01, * \star * p<$ \\
\hline
\end{tabular}

Depressive Symptomology. Results of mixed ANOVA for depression symptoms indicated a significant effect by time $[F(1,41)=21.179, p=.000$, Cohen's $d=1.44]$ and time by group $[F(1,41)=6.621, p=.014$, Cohen's $d=.80$ ]. Symptoms of depression decreased from baseline $(M=5.09, S D=4.14)$ to 3-month followup $(M=2.63, S D=2.70)$. There was no significant effect by group $[F(1,41)=3.487, p=.069$, Cohen's $d=.54]$. There was no significant difference in depression for the control condition at 3-month follow-up $[F(1,41)=2.60, p<.11$, Cohen's $d=.51]$. 
Prenatal Distress. Results of mixed ANOVA for prenatal distress showed a significant effect of time $[F(1,66)=9.219, p=.003$, Cohen's $d=.75]$. Distress decreased from baseline $(M=16.84, S D=11.17)$ to Time 2 $(M=12.24, S D=9.49)$. There were no significant difference by group $[F(1,66)=3.284, p=.75$, Cohen's $d=.44]$, nor was there a significant time by group difference $[F(1,66)=0.043, p=.836$, Cohen's $\mathrm{d}=.06]$.

PTSD Symptoms. There was a significant effect of time [ $F(1,66=4.952, p=.29$, Cohen's $d=.55]$. PTSD symptoms decreased from baseline $(M=11.97, S D=6.80)$ to 3-month follow-up $(M=9.79, S D=5.71)$. There were no significant differences by group $[F(1,66=0.004, p=.952$, Cohen's $d=.00]$ nor was there a significant time by group interaction $[F(1,66)=1.862, p=.177$, Cohen's $d=.33]$.

Transactional Sex. For transactional sex, results of mixed ANOVA showed a significant effect of time $[F(1,66)=5.061, p=.028$, Cohen's $d=.55]$. Transactional sex decreased from baseline $(M=1.37, S D=1.71)$ to 3-month follow-up $(M=.94, S D=1.21)$. There were no significant differences by group $[F(1,66=5.061$, $p=.028$, Cohen's $d=.55]$ however this effect is qualified by a time by group interaction $[F(1,66=5.698$, $p=.020$, Cohen's $d=.59]$. Transactional sex decreased from baseline $(M=1.84, S D=2.08)$ to 3-month followup $(M=.91, S D=1.2)$ for the control group $[F(1,66=10.15, p<.001$, Cohen's $d=.78]$. Transactional sex was stable from baseline $(M=.94, S D=1.19)$ to 3 -month follow-up $(M=.97, S D=1.23)$ for the POWER group $[F(1,66=0.01, p=.921$, Cohen's $d=.00]$.

\section{Discussion}

The current study explored the feasibility, acceptability, and preliminary efficacy of an innovative mindfulness-infused cognitive-behavioral intervention for young adult pregnant women in post-conflict Liberia. POWER is the first evidence-based mental and sexual health intervention that has been implemented in post-conflict Liberia. Study findings support the preliminary benefits of the intervention and the need for a larger, well-powered implementation-effectiveness trial to examine clinical effectiveness and implementation strategies that could enhance adoption and sustainment within Liberia's existing health service infrastructure.

We successfully enrolled the target number of participants, and retention rates were acceptable. Participant reported a high level of satisfaction with POWER sessions and practicing skills learned outside of the group, including meditation, muscle relaxation, deep breathing, and walking. Findings on intervention skills used most and least could inform further adaptations of POWER to best meet young pregnant Liberian women's needs. For example, we could incorporate additional mindfulness-based activities, such as pregnancy-friendly yoga poses or focusing on bodily sensations.

All Participants reported significant reductions in depression symptoms at 3-month follow-up. Findings are consistent with prior research showing mindfulness-based interventions improve maternal depression, stress, and emotion regulation skills $[28,29,30]$. Though preliminary, findings may also have implications for children's health because maternal depression during pregnancy and postpartum periods has been strongly associated with poor child development outcomes [31, 32]. 
POWER and control participants reported significantly decreased prenatal distress and PTSD symptoms at 3-month follow-up. Though speculative, the focus on cultivating mindfulness skills may have helped participants increase their distress tolerance [19]. Given the adverse consequences of prenatal distress for maternal and child health, including adverse birth outcomes, lower likelihood of breastfeeding, and deficits in children's cognitive and behavioral function $[15,13]$, effective services targeting a reduction of distress during pregnancy are essential. Findings suggest that the health education curriculum may also help reduce distress among young pregnant mothers and could be an alternative resource.

Participants reported significant reductions in frequency of transactional sex at 3-month follow-up, but there was a time by group interaction. Transactional sex decreased for those in controls only. One possible explanation is that a larger percentage of control participants reported transactional sex at baseline than did POWER participants Further adaptations and refinements to POWER may be necessary to better target reducing transactional sex, such as education about the health risks of transactional sex or strategies to secure income in healthier ways (e.g., economic empowerment).

\section{Limitations}

Study results should be viewed in light of several limitations. The sample size was small and not powered to determine clinically significant treatment effects or generalize to other populations. Longerterm benefits of POWER were also not evaluated. Including a longer follow-up period in a future wellpowered trial would provide more information on whether intervention benefits are sustained over time and whether there are intervention benefits for early childhood development outcomes. Additionally, because participants were not randomly assigned to conditions, there is the potential for sampling and selection biases.

\section{Conclusion}

Preliminary finding of POWER support feasibility, acceptability, and mental and sexual health benefits of the intervention for young pregnant Liberian women. Further investigation of POWER on a larger scale is needed to determine intervention effectiveness and ultimately expand the reach of evidence-based sexual and mental health services among young pregnant women in Liberia and other post-conflict settings to improve women's health and the health of future generations [17].

\section{Declarations}

Ethics approval and consent to participate: Informed consent was obtained from all individual participants included in the study. All methods were carried out in accordance with the necessary guidelines and regulations (Declaration of Helsinki). The study was approved by both a US-based and Liberia -based Institution Review Board: The University of Georgia's Human Research Protection Program and The University of Liberia (UL)-Atlantic Center for Research and Evaluation (ACRE) Africa. 
Consent for Publication: Not applicable for this study. All data was deidentified prior data analyses.

Availability of data and material: The data used during the current study are available by reasonable request from the corresponding author.

Competing Interests: There are no competing interest to report.

Funding: This research was funded by grants R34 MH087223 from the National Institute of Mental Health and K01TW009660 from the National Institutes of Health and Fogarty International Center. The content is solely the responsibility of the authors and does not necessarily represent the official views of the Fogarty International Center or National Institutes of Health.

Acknowledgements: The project was supported by research grants from the National Institutes of Health and Fogarty International Center R25MH083620 and 5K01TW009660-03. The content is solely the responsibility of the authors and does not necessarily represent the official views of the Fogarty International Center or National Institutes of Health. There are no known conflicts of interest. We would also like to acknowledge the study team members at Afro-Medical Community Health and Welfare Service and the University of Liberia (UL)-Atlantic Center for Research and Evaluation (ACRE) Africa for their contributions.

Authors Contributions: All authors read and approved the final manuscript. Drs. Callands and Hansen contributed to the study conception and design. Material preparation and data collection were performed by Drs. Callands, Hunter, Hansen, and Ms. Gilliam. Data analysis were performed by Drs. Callands, Desrosiers, Ms. Hylick, and Ms. Gilliam. Dr. Callands and Ms. Hylick conceptualized this manuscript. The first full draft of the manuscript was written by Drs. Callands and Ms. Hylick. Major writing, reviewing, and editing were performed by Ms. Hylick supervised by Drs. Callands and Desrosiers. Final drafts and edits were reviewed by all authors. Funding acquisition was the responsibility of Drs. Hansen and Callands.

Conflict of Interest: The authors declare that they have no conflict of interest.

Informed Consent: All participants were thoroughly informed of the study procedures, risks, and benefits.

\section{References}

1. Sileo, K. M., Kershaw, T. S., \& Callands, T. A. (2019). A syndemic of psychosocial and mental health problems in Liberia: Examining the link to transactional sex among young pregnant women. Glob Public Health, 14(10), 1442-1453. https://doi.org/10.1080/17441692.2019.1607523.

2. Johnson, K., Kennedy, S. B., Harris, A. O., Lincoln, A., Neace, W., \& Collins, D. (2005). Strengthening the HIV/AIDS service delivery system in Liberia: An international research capacity-building strategy. $J$ Eval Clin Pract, 11(3), 257-273. https://doi.org/10.1111/j.1365-2753.2005.00532.x.

3. Gwaikolo, W. S., Kohrt, B. A., \& Cooper, J. L. (2017). Health system preparedness for integration of mental health services in rural Liberia. BMC Health Serv Res, 17(1), 508. 
https://doi.org/10.1186/s12913-017-2447-1.

4. Vinck, P., \& Pham, P. N. (2013). Association of exposure to intimate-partner physical violence and potentially traumatic war-related events with mental health in Liberia. Soc Sci Med, 77, 41-49. https://doi.org/10.1016/j.socscimed.2012.10.026

5. Kelly, J., Colantuoni, E., Robinson, C., \& Decker, M. R. (2019). From political to personal violence: Links between conflict and non-partner physical violence in post-conflict Liberia. Glob Public Health, 14(12), 1639-1652. https://doi.org/10.1080/17441692.2019.1650949

6. Johnson, K. (2008). Association of combatant status and sexual violence with health and mental health outcomes in postconflict Liberia. JAMA, 300(6), 676. https://doi.org/10.1001/jama.300.6.676.

7. Atwood, K. A., Kennedy, S. B., Barbu, E. M., Nagbe, W., Seekey, W., Sirleaf, P., Perry, O., Martin, R. B., \& Sosu, F. (2011). Transactional sex among Youths in Post-conflict Liberia. J Health Popul Nutr, 29(2), 113-122. https://doi.org/10.3329/jhpn.v29i2.7853.

8. Parnarouskis, L., Stevenson, A., Lange, B. C., Pullen, S. J., Petruzzi, L. J., Dominguez, S., ... Borba, C. P. (2017). The impact of transactional sex with teachers on public school students in Monrovia, Liberia-A brief report. Vulnerable Child Youth Stud, 12(4), 328-333.

9. Callands, T. A., Sipsma, H. L., Betancourt, T. S., \& Hansen, N. B. (2013). Experiences and acceptance of intimate partner violence: Associations with sexually transmitted infection symptoms and ability to negotiate sexual safety among young Liberian women. Cult Health Sex, 15(6), 680-694. https://doi.org/10.1080/13691058.2013.779030.

10. Sipsma, H., Callands, T. A., Bradley, E., Harris, B., Johnson, B., \& Hansen, N. B. (2013). Healthcare utilisation and empowerment among women in Liberia. J Epidemiol Community Health, 67(11), 953-959.

11. Gausman, J., Lloyd, D., Kallon, T., Subramanian, S. V., Langer, A., \& Austin, S. B. (2019). Clustered risk: An ecological understanding of sexual activity among adolescent boys and girls in two urban slums in Monrovia, Liberia. Soc Sci Med, 224, 106-115. https://doi.org/10.1016/j.socscimed.2019.02.010.

12. Borba, C. P., Ng, L. C., Stevenson, A., Vesga-Lopez, O., Harris, B. L., Parnarouskis, L., ... Henderson, D. C. (2016). A mental health needs assessment of children and adolescents in post-conflict Liberia: results from a quantitative key-informant survey. Int J Cult Ment Health, 9(1), 56-70.

13. Premji, S. (2014). Perinatal distress in women in low- and middle-income countries: Allostatic load as a framework to examine the effect of perinatal distress on preterm birth and infant health. Matern Child Health J, 18(10), 2393-2407. https://doi.org/10.1007/s10995-014-1479-y.

14. Beddoe, A. E., Yang, C. P. P., Kennedy, H. P., Weiss, S. J., \& Lee, K. A. (2009). The effects of mindfulness-based yoga during pregnancy on maternal psychological and physical distress. J Obstet Gynecol \& Neonatal Nurs, 38(3), 310-319.

15. Buffa, G., Dahan, S., Sinclair, I., St-Pierre, M., Roofigari, N., Mutran, D., Rondeau, J.-J., \& Dancause, K. N. (2018). Prenatal stress and child development: A scoping review of research in low- and middleincome countries. PLOS ONE, 13(12), e0207235. https://doi.org/10.1371/journal.pone.0207235. 
16. Lever Taylor, B., Cavanagh, K., \& Strauss, C. (2016). The effectiveness of mindfulness-based interventions in the perinatal period: A systematic review and meta-analysis. PLOS ONE, 11(5), e0155720. https://doi.org/10.1371/journal.pone.0155720.

17. Firestone, R., Moorsmith, R., James, S., Urey, M., Greifinger, R., Lloyd, D., Hartenberger-Toby, L., Gausman, J., \& Sanoe, M. (2016). Intensive group learning and on-site services to improve sexual and reproductive health among young adults in Liberia: A randomized evaluation of healthy actions. Global Health Sci Pract, 4(3), 435-451. https://doi.org/10.9745/ghsp-d-16-00074.

18. Shi, Z., \& MacBeth, A. (2017). The effectiveness of mindfulness-based interventions on maternal perinatal mental health outcomes: A systematic review. Mindfulness, 8(4), 823-847. https://doi.org/10.1007/s12671-016-0673-y.

19. Frazer, C., \& Stathas, S. A. (2015). Mindfulness: Being present in the moment. Int J Childbirth Educ, $30(2)$.

20. Beaton, D. E., Bombardier, C., Guillemin, F., \& Ferraz, M. B. (2000). Guidelines for the process of crosscultural adaptation of self-report measures. Spine, 25(24), 3186-319.

21. Widman, L., Kamke, K., Evans, R., Stewart, J. L., Choukas-Bradley, S., \& Golin, C. E. (2019). Feasibility, acceptability, and preliminary efficacy of a brief online sexual health program for adolescents. J Sex Res, 57(2), 145-154. https://doi.org/10.1080/00224499.2019.1630800.

22. Stephenson, R., Metheny, N., Goldenberg, T., Bakunina, N., De Vasconcelos, S., Blondeel, K., Kiarie, J., \& Toskin, I. (2020). Brief intervention to prevent sexually transmitted infections and unintended pregnancies: Protocol of a mixed methods feasibility study. JMIR Research Protocols, 9(3), e15569. https://doi.org/10.2196/15569.

23. Kroenke, K., Spitzer, R. L., \& Williams, J. B. (2001). The PHQ-9: Validity of a brief depression severity measure. J Gen Intern Med, 16(9), 606-613.

24. Alderdice, F., \& Lynn, F. (2011). Factor structure of the prenatal distress questionnaire. Midwifery, 27(4), 553-559.

25. DeMarco, F. J., Ostrow, D. G., \& DiFranceisco, W. (1999). General and AIDS-specific stress, coping, and psychological distress in the biracial coping \& change study cohort of gay men. AIDS Beh, 3(3), 177186.

26. Weathers, F. W., Litz, B., Huska, J. A., \& Keane, T. M. (1994). PCL-C for DSM-IV (PTSD Checklist). National Center for PTSD.

27. Dunkle, K. L., Wingood, G. M., Camp, C. M., \& DiClemente, R. J. (2010). Economically motivated relationships and transactional sex among unmarried African American and white women: Results from a U.S. national telephone survey. Public Health Rep, 125(4_suppl), 90-100. https://doi.org/10.1177/00333549101250s413.

28. Davis, D. M., \& Hayes, J. A. (2011). What are the benefits of mindfulness? A practice review of psychotherapy-related research. Psychotherapy, 48(2), 198-208. https://doi.org/10.1037/a0022062.

29. Keng, S.-L., Smoski, M. J., \& Robins, C. J. (2011). Effects of mindfulness on psychological health: A review of empirical studies. Clin Psychol Rev, 31(6), 1041-1056. 
https://doi.org/10.1016/j.cpr.2011.04.006.

30. Hall, H., Beattie, J., Lau, R., East, C., \& Biro, M. A. (2015). The effectiveness of mindfulness training on perinatal mental health: A systematic review. Integr Med Res, 4(1), 125. https://doi.org/10.1016/j.imr.2015.04.233.

31. Gelaye, B., Rondon, M. B., Araya, R., \& Williams, M. A. (2016). Epidemiology of maternal depression, risk factors, and child outcomes in low-income and middle-income countries. Lancet Psychiat, 3(10), 973-982. https://doi.org/10.1016/s2215-0366(16)30284-x.

32. Herba, C. M., Glover, V., Ramchandani, P. G., \& Rondon, M. B. (2016). Maternal depression and mental health in early childhood: An examination of underlying mechanisms in low-income and middleincome countries. Lancet Psychiat, 3(10), 983-992. https://doi.org/10.1016/s2215-0366(16)301481. 